\title{
Advances In Natural And Applied Sciences
}

\section{Implementation of Chemical Reaction Based on Augmented Reality}

\section{Alexander Setiawan, Silvia Rostianingsih and Timotius Reinaldo Widodo}

Informatics Department, Faculty of Industrial Technology, Petra Christian University Indonesia, Siwalankerto Street 121-131 Surabaya 60236 Indonesia

Correspondence Author: Alexander Setiawan, Informatics Department, Faculty of Industrial Technology, Petra Christian University Indonesia, Siwalankerto Street 121-131 Surabaya 60236 Indonesia

Received date: 12 January 2018, Accepted date: 10 March 2018, Online date: 2 April 2018

Copyright: (C) 2018 Alexander Setiawan et al. This is an open-access article distributed under the terms of the Creative Commons Attribution License, which permits unrestricted use, distribution, and reproduction in any medium, provided the original author and source are credited.

\begin{abstract}
One of the interesting technologies today that can be developed on a smart phone is Augmented Reality (AR). AR is capable of supplying information that is easy to understand by the users. The benefit above can be used to make a learning application to support a learning process. One lesson that can make use of this technology is chemistry, specifically about chemical reactions. On this research, a chemical reaction learning application that utilizes library vuforia and Unity by using C\# programming language will be made. Along with the 3D object creation is made by an application called Blender. The test result shows that applications that are made by using library vuforia and Unity can run well. High school students are able to picture the chemical reactions by using this application.
\end{abstract}

Key words: Chemical Reaction, Android, Virtual Reality

\section{INTRODUCTION}

Technology is made to facilitate human finishing or doing its activities. One technology that is currently widely used is mobile phones. The mobile phone technology itself has grown quite rapidly, in addition to its main function to communicate either phone or messaging, mobile phones nowadays have many features that can be utilized for playing games, watching videos, listening to music, personal assistant, looking for information, GPS, and still much more.

One interesting technology that can be developed on mobile phones is Augmented Reality. Augmented Reality is a technology that combines twodimensional or three-dimensional virtual objects into a real three-dimensional environment and projects those virtual objects in real time.

Augmented Reality has many benefits that can be applied in various fields, including health, manufacturing and reparations, entertainment, military, and education. Augmented Reality can provide a picture / information that can be more easily understood by the user / user. Because of its advantages, Augmented Reality can be utilized to create learning applications that can support teaching and learning process.

Chemical learning about chemical reactions is usually boring by children. This is because children only know the theory of books and teacher explanations only. Therefore, with the creation of applications that utilize Augmented Reality, children are expected to be more interested and enthusiastic to learn chemical reactions because with applications that utilize Augmented Reality children can see 3D models of these chemical elements and also see the merger between elements.

\section{Applications Theory:}

2.1. Augmented Reality $(A R)$ :

Augmented Reality (AR) is a variation of the Virtual Environment (VE) or commonly known as Virtual Reality [1]. AR is the incorporation of real and virtual objects in real environments, running interactively in real time and there is integration between objects. AR technology is different from VE technology. VE technology will take the user into the unreal world entirely, while AR still allows the user / user to keep seeing the real world with virtual objects superimposed or incorporated into the real world [2]. Three characteristics for Augmented Reality according to: [1]

- Augmented Reality combines Real and Virtual Information.

- Augmented Reality Interactive in the real world.

- Augmented Reality operates and is used in 3D environments.

Some of the components required in the manufacture and development of Augmented Reality applications are as follows: [3]

- Hardware, there are :

o Computer (PC/Mobile)

o Head Mounted Display (HMD)

o Camera

- Software, there are:

o Application

o Web Service

o Content Centre

- Marker

An example marker is shown in Figure 1. 
Fig. 1: Example Marker.

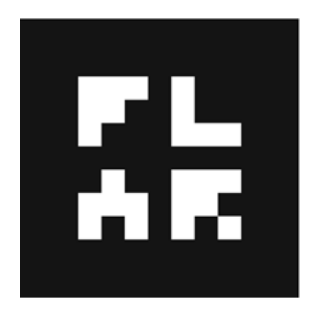

2.2 Unity:

Unity is a flexible and strong development platform. It is used to develop 2D and 3D multiplatform games interactively. It can also develop $2 \mathrm{D}$ or 3D multiplatform application for Android, iOS, and web as well.

Unity creates object, import external assets, and connects everything with coding efficiently and very fast. User can do everything by simple drag-and-drop motion that are connected with script, set variables, or create complex multi-part assets [4] Figure 2 shows usage of Augmented Reality by using Unity.

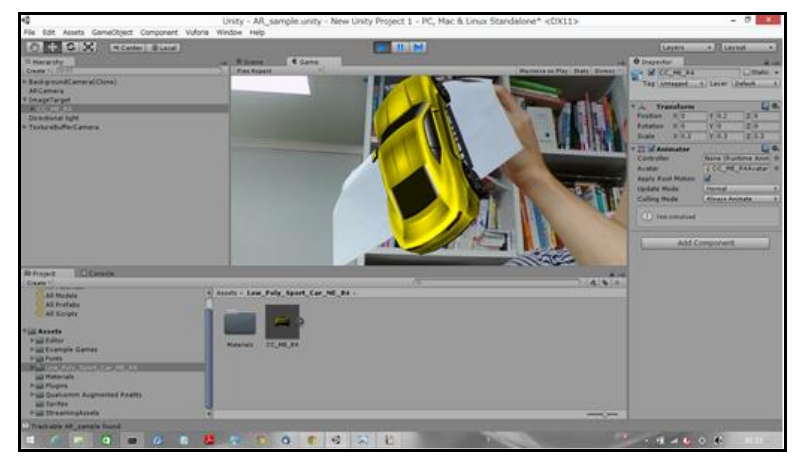

Fig. 2: Example Augmented Reality Unity.

\subsection{Vulforia:}

Vuforia is a software platform that allows applications to see. Developer can certainly add functionality of Vuforia to several applications so that objects and images can be recognized or to reconstruct environment in the real world. Vuforia eases the process of making applications that use Augmented Reality to obtain virtual impression of a product.

Algorithm of Vuforia is targeted at objects recognizing and tracking, including fiducials (frame marker), image targets, bahkan object 3D [5]. Besides, it can also do tracking for multi-targets, cylinder targets, and text recognition.

Target at Vuforia is an object from the real world that can be detected by a camera to display the virtual object [6].

2.4 Blender:

Blender is an open source application that is used for making the 3D modelling. Blender can create character, props, environment, and any kinds of imaginations as well. This application does not just create objects, but it can also make animations of modelling that have been made [7].

\subsection{Chemical:}

Chemical bonding is a bonding that is formed between atoms or molecules by releasing one's electrons, while the other receives electrons (electrons handover), joint use of electron pairs derived from the respective bonding atoms, the joint use of electron pairs derived from one of the bonded atoms.

The objective of chemical bonding formation is to achieve the stability of an element. The stability of the element occurs when an element follows the octet rule. The Octet rule is the tendency of elements to make the electron configuration the same as noble gases. The noble gas element (Group VIIIA) has 8 (octets) or 2 valence electrons (duplet, only Helium element). Figure 3 shows periodic table of the elements chemical.

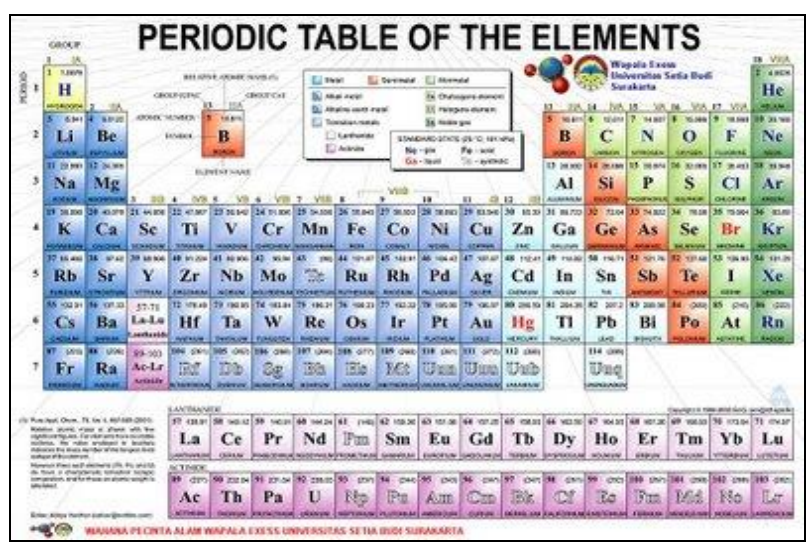

Fig. 3: Periodic Table of The Elements Chemical.

3 System Design:

3.1. Planning Applications:

The application will start with the Main Menu view of the start button to run the main application and exit button to exit the application and there is a button to open the description page. Figure 4 shows the general flowchart of the application. 


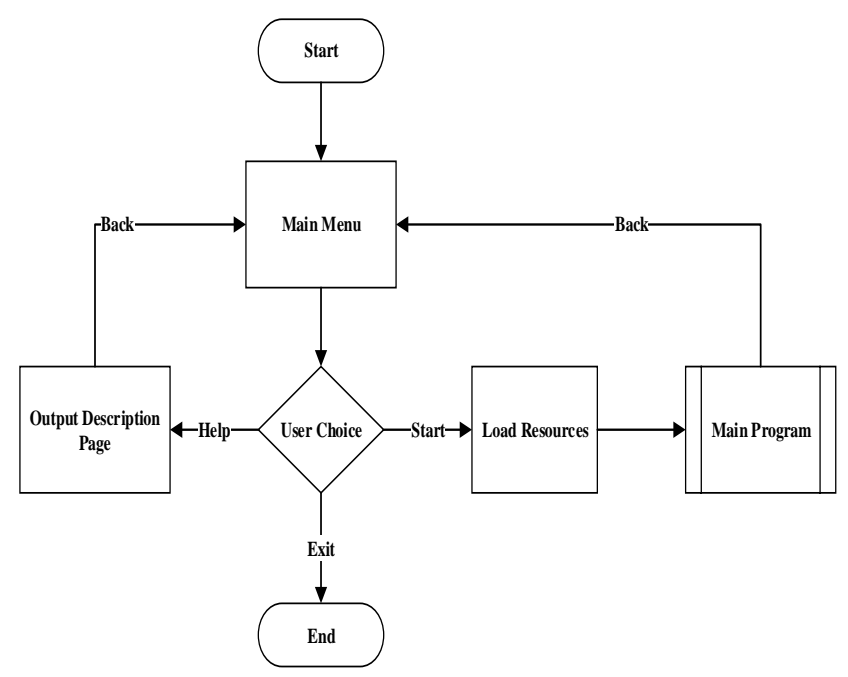

Fig. 4: Common Flowchart.

The main program will turn on the camera on the mobile then the user can direct the camera to the desired marker. When the marker has been readable and detected by the camera it will show 3D objects on the mobile application screen. 3D objects that have interactions with other objects can do a merge animation if the marker is brought closer. Another feature that exists in this application is 3D objects can be zoomed in and scaled down and played using 2 fingers touching the screen of mobile applications. Figure 5 shows an overview of the flow of the application's main program.

\section{Fig. 5: Main Application Flowchart}

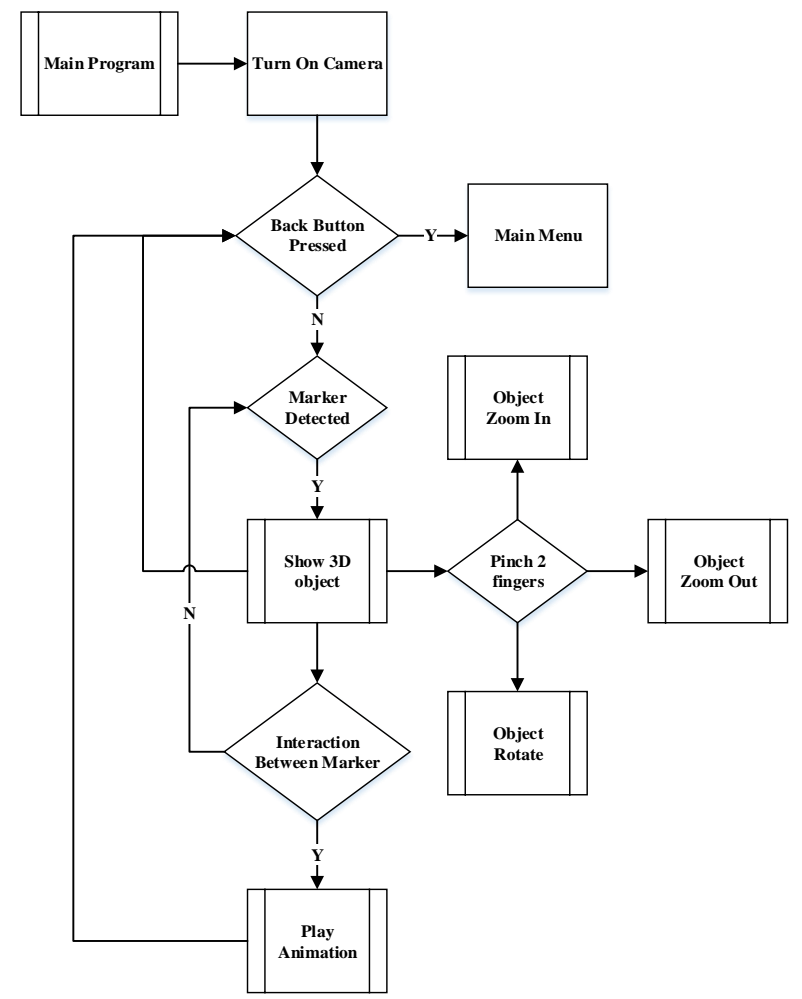

The marker used in this "Chemical Reaction" learning app is in the form of a hexagon card that made simple but still interesting. Card design / marker used in this application can be seen in Figure 6 .

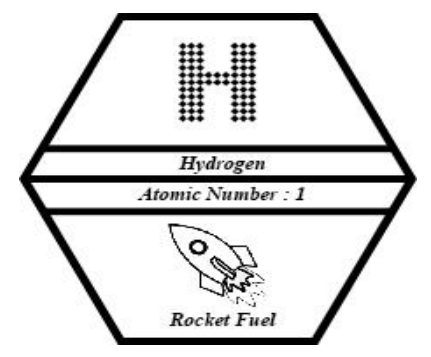

Fig. 6: Markers Design 


\section{Testing And System Implementation:}

4.1. 3D-Object Merge Testing:

Testing of 3D object merging is done with 2 reacting objects and 3 reacting objects. Applications can merge up to 8 objects.

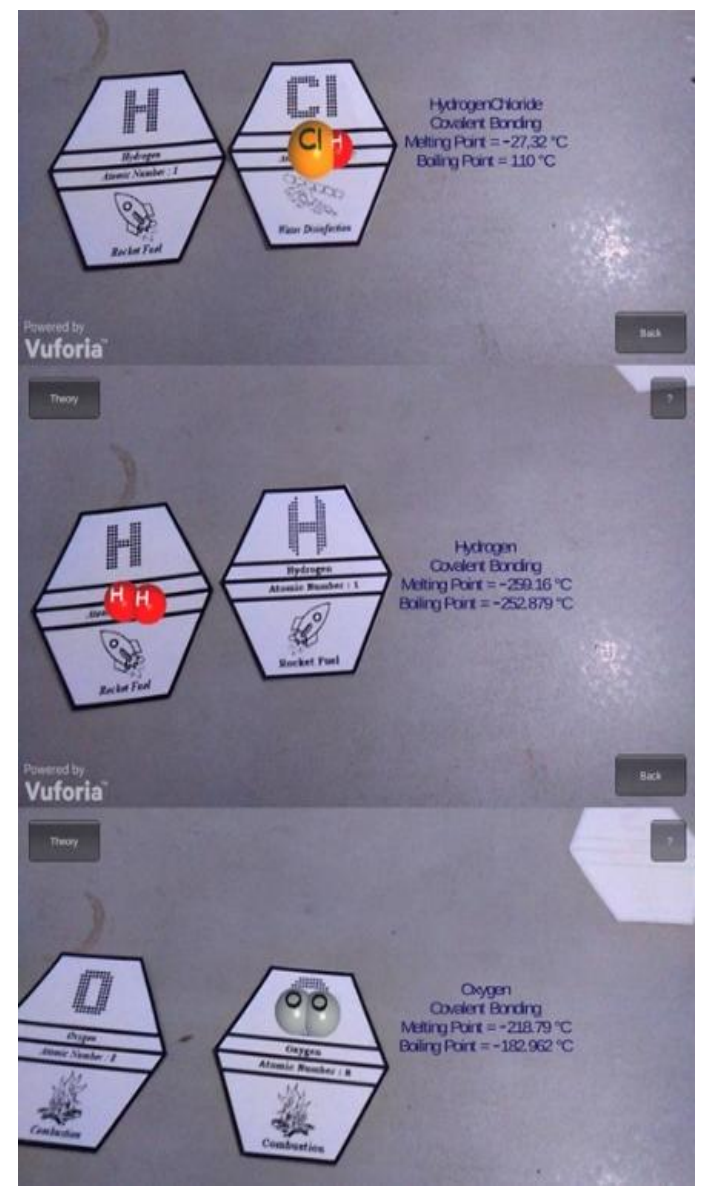

Fig. 7: Two Object's Reaction

Figure 7 shows the test to see what happens when 2 markers that have a reaction are detected and the object reacts. The image shows how objects will move and join other objects if they are linked to each other.

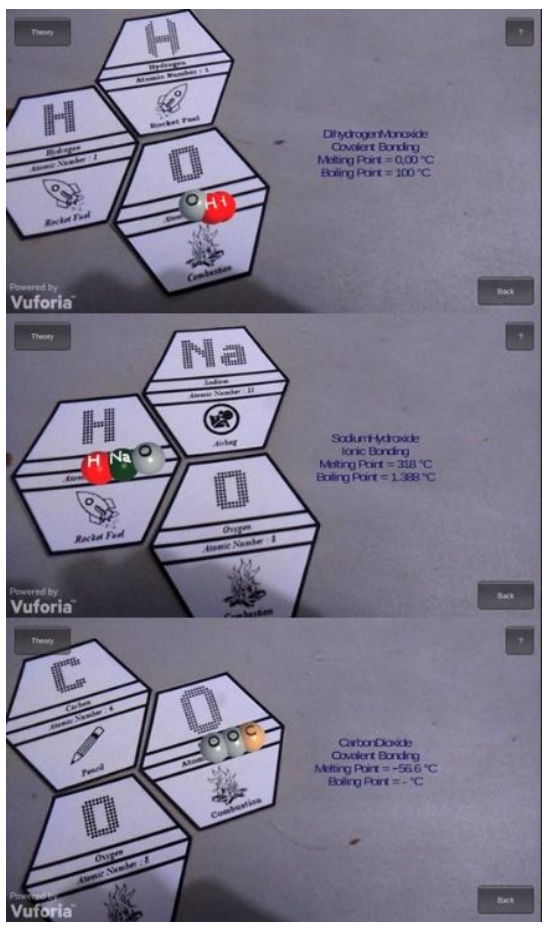

Fig. 8: Three Objects Reaction 
Citation: Alexander Setiawan, Silvia Rostianingsih and Timotius Reinaldo Widodo, 2018. Implementation of Chemical Reaction Based On Augmented Reality. Advances in Natural and Applied Sciences., 12(4): 22-26. relation.

Figure 8 shows the test to see what happens when 3 markers that have a reaction are detected. Objects that have a reaction will move toward the object of the

4.2. 3D-Object Transformation Testing:

Testing is done to see if 3D objects can be enlarged, reduced and rotated. This test works because 3D objects can be enlarged, reduced and rotated.

\subsection{Bring Up Elemental Information:}

Testing is done to see if the description that comes out for each chemical element is correct. The description shown in the application is element name, atomic number, mass number, oxidation number, and elemental form.

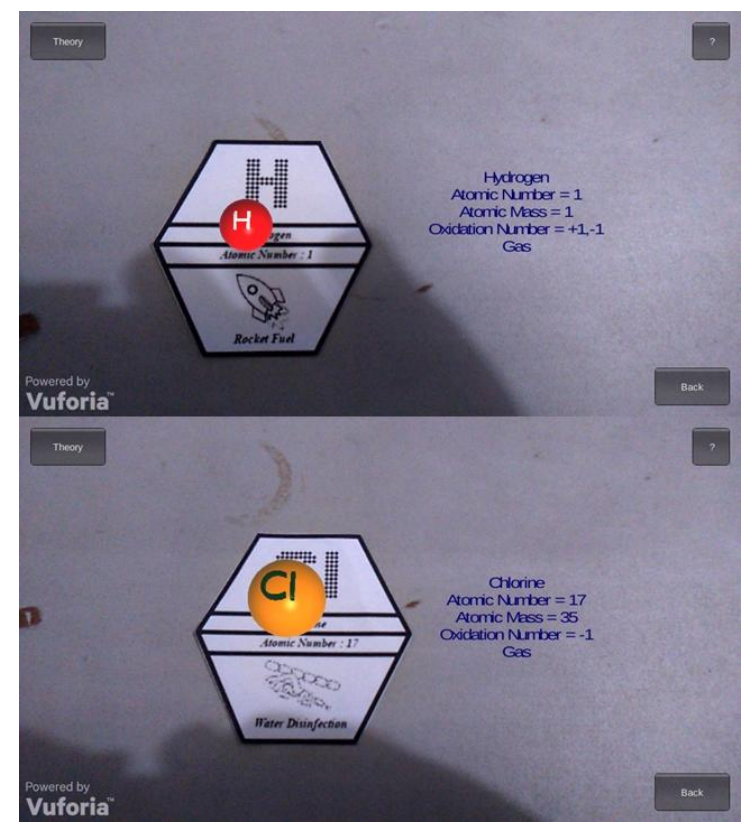

Fig. 9: Element's Description

Figure 9 shows the accuracy test description shown for each element. The description displayed by the application is appropriate for each element as shown in Figure 8, that when the $\mathrm{H}$ element object that appears the description shown is the description for element $\mathrm{H}$ and when the $\mathrm{Cl}$ element object appears, the description shown is the description for the $\mathrm{Cl}$ element. In addition to each element, the description that can be displayed in the application is the description of the compound when the element object combines to form a compound. A description for the compound represented by the application is the name of the compound, the type of bond, the melting/melting point and the boiling point.

Conclusion:

Based on the results of the test, it can be concluded several things as follows:

- Marker's detection by mobile camera are already work well. Marker can be detected, and the application can show the 3D object.

- Chemical reaction process is already well for combination 2 and 3 elements and can get 50 combinations for the element.

- Transformation for 3D object is already work well, it can be enlarged, reduced, and rotated.

\section{REFERENCES}

[1] Azuma, Ronald T., 1997. "A Survey of Augmented Reality”. Presence: Teleoperators and Virtual Environments.

[2] Kipper, Greg., dan Joseph Rampolla, 2013. Augmented Reality: An Emerging Technologies Guide to AR. United States: Elsevier.

[3] Martono, K.T., 2011. "Augmented Reality Sebagai Metafora Baru dalam Teknologi Interaksi Manusia dan Komputer”. Semarang, Indonesia: JURNAL SISTEM KOMPUTER (JSK)

[4] Menard, Michelle., dan Bryan Wagstaff, 2014. Game Development with Unity, Second Edition. United States: Cengage Learning.

[5] Grubert, Jens., dan Dr. Raphael Grasset, 2013. "Augmented Reality for Android Application Development”. Birmingham, UK: Packt Publishing Ltd.

[6] Ibañez, Alexandro S., dan Josep P. Figueras, 2013. "Vuforia v1.5 SDK: Analysis and evaluation of capabilities". http://upcommons.upc.edu/bitstream/handle/2099.1/17769/memoria.pdf. Diakses pada tanggal.

[7] Gumster, Jason van, 2015. Blender For Dummies, 3rd Edition. Hoboken, New Jersey: John Wiley \& Sons, Inc. 